\title{
СИСТЕМНЫЙ ПОДХОД К ПРОБЛЕМЕ МОТИВАЦИИ ПЕРСОНАЛА ${ }^{1}$
}

\author{
(C) 2012 г. В. Н. Гарькуша, Н. А. Чвикалова
}

\section{Южно-Российский государственный технический университет (НПИ)}

Проанализирован системный подход к проблеме мотивации персонала на основе использования модели организационных взаимосвязей Мак-Кинзи «7S». Рассмотрень важнейшие факторы данной модели. Показана связь стратегии развития и функиионирования организации и системы мотивачии персонала. Установлено, что в современных условиях экономического развития для большинства организачий приоритетным направлением их развития является разработка и внедрение инноваций, что целесообразно закрепить в стратегии организации и в разрабатываемых системах мотиваџии персонала.

Ключевые слова:системный подход; модель Мак-Кинзи «7S»; стратегия развития организации; мотивация персонала; инновационное развитие.

Authors analyzed the system approach to the problem of personnel's motivation. As a basis of the analysis they used McKinsey $7 S$ Framework. The most important features of the model are also examined. The interrelations between organization's strategy of functioning and development and its systems of personnel's motivation are shown. It's proved that the conditions of nowadays economy make working out and adoption of the innovations a higher-priority way of the development, and this way should be included into the organization's strategy and into the systems of personnel's motivation, which the organization works out.

Key words: system approach; McKinsey 7S Framework; organization's development strategy; personnel's motivation; innovation development.

Мотивация персонала с позиций системного подхода предполагает всесторонний учет психологических особенностей как индивидуальной, так и групповой деятельности, а также в соответствии со стратегией развития и функционирования организации использование действенных методов мотивации привлечения, удержания персонала и эффективного труда.

Нам представляется, что наиболее полно такой подход к проблеме мотивации персонала реализуется на основе использования модели организационных взаимосвязей МакКинзи «7S». Модель Мак-Кинзи не дает четких рекомендаций по созданию и развитию бизнеса или планированию стратегии, эта модель предполагает комплексный анализ взаимосвязей в процессе развития и функционирования организации. Она представляет собой эффективный способ осмысления проблем развития и функционирования организации.

Т. Питерс и Р. Уотерман выделяют семь основных факторов, которые необходимо охватывать и рассматривать как взаимозависимые [1]:

- стратегия (strategy);

- сумма навыков, умений (skill);

- структура (structure);

- системы (systems);

- состав работников, т. е. кадры (staff);

— стиль(style);

- совместные, т. е. разделяемые всеми ценности (shared values).

1 Результаты работы получены при поддержке Минобрнауки РФ в рамках государственного задания на проведение НИОКР, шифр заявки 6.2989.2011 
Практика использования данной модели для развития и функционирования организации предполагает такую последовательность изменения семи составляющих.

На первом этапе анализа взаимосвязей менеджмент организации обосновывает стратегию. Стратегия определяет, каким образом и где должна конкурировать организация, т. е. что должны делать члены организации в целом и конкретно каждый член организации, на чем организация должна сосредоточить свои усилия и знания, чтобы добиться отличительных особенностей и успешного развития и функционирования.

Когда менеджмент организации четко сформулирует стратегию, далее необходимо определить, какие знания, умения и функциональные навыки потребуются для ее осуществления. С этой целью необходимо провести стратегический анализ внутренней среды организации и определить, в чем сильна организация, какие умения и навыки надо развить или сформировать, для того чтобы эффективно реализовать стратегию.

Стратегия может определять, с одной стороны, как используя свой потенциал, организация должна приспособиться к внешнему окружению, и, с другой стороны, как развить свой потенциал, чтобы реализовать ту стратегию, которая сформулирована менеджментом организации с учетом опережающей адаптации к окружающей среде.

Функциональные навыки и умения представляют собой взаимосвязь между стратегией и новым образом организации и их надо развивать так, чтобы они обеспечили успешную деятельность. Это условие накладывает на организацию определенные ограничения, и она оказывается в состоянии заниматься развитием не более одного - трех навыков, которые определяют те изменения, которые должны произойти в следующих пяти «S»: в структуре, системах, штатах, стиле и совместных, общепризнанных ценностях. Поэтому, чтобы все перемены привели к положительному результату, необходимо определить, что требуется изменить в оставшихся пяти факторах.

Среди концепций, касающихся изменений организационных взаимосвязей организации, наиболее известны концепции изменения ее организационной структуры. В них представлены взаимосвязи, складывающиеся между различными направлениями бизнеса, отделениями организаций и ее подразделениями. Эти взаимосвязи являются наиболее заметным, видимым организационным фактором, и поэтому чаще всего изменения начинают именно со структуры. Однако реорганизовать организацию и повысить эффективность ее функционирования путем одних структурных изменений невозможно. Тем не менее, тесную связь и влияние стратегии и структуры доказал еще в начале 1960 -х годов А. Чандлер в работе «Стратегия и структура» [2]. Он утверждал, что изменения в стратегии неизменно влекут за собой изменения и в структуре. И наоборот, после изменений в структуре, т. е. после перехода к новой организационной структуре управления, начинается следующий цикл изменений: стратегии меняются вследствие изменений во взаимосвязях и, соответственно, в стратегическом мышлении, обусловленном новым этапом развития.

Под системами в Мак-Кинзи понимают установленный порядок, или бизнес-процессы, которые в руках менеджеров являются сильным инструментом осуществления перемен и происходят в организации с привлечением многих людей, принимающих решения, выполняющих различные виды работ и т. д. Bce, что осуществляется в организации, является следствием результативности существующих систем.

Фактор кадров или состава работников связан с решением вопроса о том, какие люди нужны организации, какого типа организационного поведения. И это проблема общего ноу-хау организации, а не столько проблема отдельных работников.

Стиль формируется в соответствии с системой ценностей руководителя и состоит, как правило, из двух составляющих: личного стиля и конкретных действий - символов. Проблема стиля организации не может быть сведена лишь к проблеме личного стиля руководителя. Использование исполнителями своей личной сигнальной информации в процессе деятельности оказывает формирование и на стиль организации.

Общепризнанные ценности, лежащие в основе формирования корпоративной культуры, имеют решающее значение для выжива- 
ния, и тем более для успешного развития организации в долгосрочной перспективе. Они связаны с тем, что представляется главным в образе организации с точки зрения общества, потребителей, персонала.

Таким образом, модель организационных взаимосвязей Мак-Кинзи «7S» определяет после принятия конкретной стратегии последовательность внутренних действий организации по ее реализации.

Такие действия включают:

a) планирование основных внутренних факторов организации, соответствующих конкретной стратегии, а именно - необходимых функциональных навыков и культуры;

б) установление вторичных от функциональных навыков и культуры факторов:

- структуры - организационные схемы, коммуникационные взаимосвязи, описание работ, линии субординации;

- системы - оплаты труда и стимулирования персонала, потоки работ в организации, процедуры исполнения, учета и контроля;

- штата сотрудников - менеджмент организации определяет, какой тип сотрудников ей нужен, какие именно профессиональные работники и в каком количестве ей необходимы;

- стиля - характеризует стиль организации в целом, личный стиль руководства, стиль и характер поведения сотрудников организации.

Модель организационных взаимосвязей «7S» важна тем, что процесс планирования деятельности организации понимается как установление взаимосвязи и согласия между сотрудниками, как увязка их интересов, учет всех сторон деятельности человека в организации. Использование этой модели предполагает, что процесс планирования деятельности организации - не столько процесс создания формальных схем и совокупности количественных показателей, сколько процесс планирования успеха.

В современных условиях экономического развития для большинства организаций приоритетным направлением их развития является разработка и внедрение инноваций, что целесообразно закрепить в стратегии организации. Стратегия должна представлять собой четко сформулированное направление дви- жения организации из того состояния в котором она находится сегодня, в то состояние, в каком хочет видеть ее высший менеджмент организации, а также систему взаимоувязанных и сбалансированных целей. Причем эти цели должны быть реалистичны, подкреплены конкретными размерами необходимых ресурсов (финансовых, материальных, трудовых и т. д.) и временем, необходимым на достижение этих целей [3].

Инновационное развитие особенно важно для организаций, производящих товары и услуги для широкого потребления, для которых изменение вкусов и предпочтений потребителей может оказаться губительным по своим последствиям. Именно поэтому инновации представляют собой результат взаимодействия маркетинга и технологий: изучение и формирование спроса на основе новейших технологий.

Т. Питерс и Р. Уотерман сформулировали восемь признаков, которые наиболее полно характеризуют отличительные особенности образцовых, склонных к нововведениям компаний [1]:

1. Ориентация на действия, на достижение успеха. Инновационные компании, сталкиваясь с проблемами, создают группы по 5-25 человек для генерации новых идей, которые они проверяют на потребителе, часто с использованием недорогих опытных образцов.

2. Лицуом к потребителю. Образцовые компании учатся у людей, для которых они производят продукцию, оказывают услуги. Многие из новаторских компаний почерпнули идеи своих лучших продуктов от потребителей. При этом они предлагают высокое качество, обслуживание и надежность - всегда что-то, что служит долго и хорошо. В образцовых компаниях каждый участвует в общем деле планирования и реализации успеха.

3. Самостоятельность и предприимчивость. Склонные к нововведениям компании создают такие системы организации, чтобы было много лидеров и новаторов. Они поддерживают удачные начинания, не наказывают за единичные провалы и поощряют оправданную степень риска.

4. Производительность - от человека. Образцовые компании, реализуя принцип партисипативности, рассматривают рядовой 
персонал как главный источник достижений в области качества и производительности. Они не считают основным источником повышения эффективности капиталовложения и не поддерживают установки типа «мы и они» в области трудовых отношений. В образцовых компаниях каждый рабочий «рассматривается как источник идей, а не просто как действующая пара рабочих рук».

5. Ценностное руководство и связь $c$ жизнью. В образцовых компаниях, технологические, экономические ресурсы, организационная структура, нововведения, соблюдение сроков являются важными элементами производственной и организационной культуры. Но основная философия организации играет гораздо большую роль в ее достижениях и успехе.

6. Верность своему делу. Образцовые компании добиваются высокой эффективности прежде всего потому что разумно придерживаются того дела, которое они знают, хотя и имеются исключения. Менеджмент таких кампаний, как правило, придерживаются принципа: «Никогда не вступайте в дело, если не знаете, как его вести».

7. Простота форм, скромный штат. Образцовые компании имеют немногочисленный высший уровень управления. Внутренние структурные формы и системы компаний, склонных к нововведениям, также отличаются простотой и изяществом. Образцовые компании, как правило, имеют штабквартиру численностью до 100 человек, которые управляют предприятиями с многомиллиардными оборотами.

8. Свобода и жесткость одновременно. С одной стороны, образцовые компании являются фанатичными централистами в том, что касается немногих коренных ценностей, которые они провозглашают и которым они следуют. С другой стороны, образцовые компании предстают одновременно и централизованными и децентрализованными. Они, как правило, распространяют автономию вплоть до цехов и групп разработчиков продуктов.

Как отмечают Т. Питерс и Р. Уотерман, большинство из перечисленных восьми признаков - отнюдь не сенсационная новинка. Некоторые из них, если не большая часть, Поступила в редакциию являются почти прописными истинами. Но, несмотря на то, что принято считать сотрудников «самым ценным капиталом», почти никто из менеджеров по-настоящему не действует в соответствии с этим утверждением. Образцовые компании уделяют много внимания своим обязательствам перед персоналом, они предпочитают действия (любые действия) бесчисленным комиссиям «по вопросу о...» и бесконечным «исследованиям». Они настойчиво требуют постоянной инициативы (практической самостоятельности) от десятков тысяч сотрудников, а не только от двухсот специально назначенных «мыслителей» с высокой оплатой.

Таким образом, после выбора определенной стратегии, направленной на нововведения, целесообразно проанализировать существующую организационную культуру и определить, какая организационная культура в большей степени соответствует выбранной стратегии, какой персонал и какой стиль руководства могут обеспечить эффективность реализации стратегии, какие необходимы структура и система организации, какие требуются опыт и ресурсы.

Вышеизложенное свидетельствует о том, что при реализации стратегии организации, направленной на создание и внедрение инноваций, на первое место выходят такие качества персонала как профессионализм, способность к творчеству, интеллектуальные способности, наличие интуиции, оправданная степень риска, коммуникативные качества, психофизиологические и социально-демографические характеристики, которые должны найти отражение в разрабатываемых системах стимулирования труда.

\section{Литература}

1. Питерс T., Уотермен Р. В поисках эффективного управления. / Пер. с англ. под ред. Л. И. Евенко. - М.: Прогресс, 1986. - 419 с.

2. Chandler A. D. Strategy and Structure. Cambridge, Mass: MIT Press, 1962.

3. Уотермен Р. Фактор обновления: как сохраняют конкурентоспособность лучшие компании. / Пер. с англ. под ред. В. Т. Рысина. - М.: Прогресс, 1988. - 363 с.

24 февраля 2012 г. 


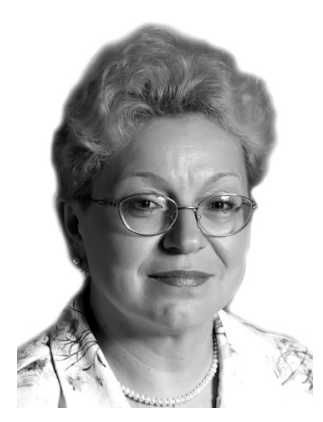

Валентина Николаевна Гарькуша - кандидат экономических наук, доцент кафедры «Производственный и инновационный менеджмент» Южно-Российского технического университета (Новочеркасского политехнического института). Автор ряда работ по проблемам планирования, стратегического менеджмента и страхования.

Valentina Nikolaevna Garkusha - Ph.D., candidate of economics, docent of SRSTU (NPI) «Production Management and Management of the Innovations» department. Author of numerous works, dedicated to problems of planning, strategic management and insurance.

346428, г. Новочеркасск, ул. Просвещения, 132

132 Prosveshcheniya st., 346428, Novocherkassk, Rostov reg., Russia

Тел.: +7 (8635) 25-51-54; факс: +7 (8635) 25-56-66; e-mail: eiup@npi-tu.ru

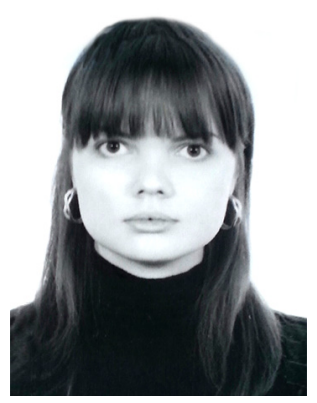

Наталья Александровна Чвикалова - магистрант Высшей школы управления Южно-Российского технического университета (Новочеркасского политехнического института), направление «Менеджмент».

Natalia Aleksandrovna Chvikalova - postgraduate at South-Russian State Technical University (NPI) Higher School of Managament, studies program «Management».

346428 , г. Новочеркасск, ул. Просвещения, 132

132 Prosveshcheniya st., 346428, Novocherkassk, Rostov reg., Russia

Тел.: +7 (8635) 25-51-54; факс: +7 (8635) 25-56-66; e-mail: eiup@npi-tu.ru 